\title{
Microcystic Adenoma
}

National Cancer Institute

\section{Source}

National Cancer Institute. Microcystic Adenoma. NCI Thesaurus. Code C3685.

A benign epithelial neoplasm characterized by a microcystic pattern. The cystic spaces

are lined by small cuboidal cells without evidence of significant cytologic atypia. 